Рецензия на книгу / Book Review

УДК 82.09

ББК 83
О СЛАВЕ, ПЛАЧЕ И ФОРМУЛАХ. РЕЦЕНЗИЯ НА ИЗДАНИЕ: «ПАМЯТНИКИ КНИЖНОГО ЭПОСА ЗАПАДА

И ВОСТОКА»: КОЛЛЕКТИВНАЯ

МОНОГРАФИЯ / СОСТ. И РЕД.

С.Ю. НЕКЛЮДОВ, Н.В. ПЕТРОВ.

М.: ИНФРА-М, 2018.482 C.

(C) 202I г. И.К. Стаф

Институт мировой литературы им. А.М. Горького

Российской академии наук, Москва, Россия

Дата поступления статьи: 03 июля 2020 г.

Дата одобрения рецензентами: 22 октября 2020 г. Дата публикации: 25 июня 2021 г.

https://doi.org/IO.22455/2500-4247-202I-6-2-478-49I

Аннотация: Коллективная монография, подготовленная С.Ю. Неклюдовым и

Н.В. Петровым, посвящена проблемам книжного эпоса - памятникам древней и средневековой словесности, промежуточным между фольклором и литературой; устная традиция в них преломляется и трансформируется в процессе письменной фиксации. Изучение книжного эпоса позволяет ставить и решать проблемы, далеко выходящие за рамки эпосоведения: в книге поднимаются вопросы, связанные не только со становлением и особенностями одного из жанров или родов литературы, но и с зарождением литературы как таковой, ее социально-культурной ролью в различные эпохи, соотношением традиции и индивидуального авторства, эволюцией поэтической техники, способами и обстоятельствами циклизации эпических сказаний. Этот капитальный труд представляется заметным событием в мировой науке.

Ключевые слова: эпос, фольклор, письменная фиксация, формульное повествование, типология, мотив.

Информация об авторе: Ирина Карловна Стаф - кандидат филологических наук, старший научный сотрудник, Институт мировой литературы им. А.М. Горького Российской академии наук, ул. Поварская, д. 25 а, І2Іо69 г. Москва, Россия. ORCID ID: https://orcid.org/oooo-0003-3975-66I7

E-mail: irina.staf@gmail.com

Для цитирования: Стаф И.К. О славе, плаче и формулах. Рецензия на издание:

«Памятники книжного эпоса Запада и Востока»: коллективная монография / сост. и ред. С.Ю. Неклюдов, Н.В. Петров. М.: Инфра-М, 2018. 482 с. // Studia Litterarum. 202I. T. 6, № 2. С. 478-49I. https://doi.org/I0.22455/2500-4247-202I-6-2-478-49I 


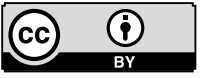

This is an open access article distributed under the Creative Commons Attribution 4.0 International (CC BY 4.0)

Studia Litterarum, vol. 6, no. 2, 202I

\section{ABOUT GLORY, CRYING AND FORMULAS. REVIEW OF: MONUMENTS OF THE BOOK EPIC OF WEST AND EAST, ED. BY S.YU. NEKLYUDOV, N.V. PETROV. MOSCOW, INFRA-M PUBL., 2018. 482 P.}

(C) 202I. Irina K. Staf

Abstract: The reviewed collective monograph edited by S. Neklyudov and N. Petrov focuses on issues of the book epic, monuments of ancient and medieval genre in between folklore and literature; the oral tradition in them is refracted and transformed in the process of written fixation. The research of the book epic makes it possible to set and solve problems far beyond the scope of epic studies: the book raises issues related not only to the formation and features of one of the literary genres, but also to the emergence of literature as such, its socio-cultural role in different epochs, the relationship between tradition and individual authorship, the evolution of poetic technique, the ways and circumstances of cycling epic tales. This capital work appears to be a remarkable event in world science.

Keywords: epic, folklore, written fixation, formulaic narration, typology, motive.

Information about the author: Irina K. Staf, PhD in Philology, Senior Researcher, A.M. Gorky Institute of World Literature of the Russian Academy of Sciences, Povarskaya 25 a, I21069 Moscow, Russia.

ORCID ID: https://orcid.org/oooo-0003-3975-66I7

E-mail: irina.staf@gmail.com

For citation: Staf, I.K. "About Glory, Crying and Formulas. Review of: Monuments of the Book Epic of West and East, ed. by S.Yu. Neklyudov, N.V. Petrov. Moscow, INFRA-M Publ., 20I8. 482 p." Studia Litterarum, vol. 6, no. 2, 202I, pp. 478-49I. (In Russ.) https://doi.org/I0.22455/2500-4247-202I-6-2-478-49I 
Монография, выпущенная под редакцией двух ведущих специалистов по изучению эпической словесности, продолжает и существенно развивает традицию, заложенную в отечественной филологии более сорока лет назад книгой «Памятники книжного эпоса. Стиль и типологические особенности» [5]. В одиннадцати ее главах обстоятельно описаны в свете последних достижений науки эпические памятники - от древнейшего (II тыс. до н.э.) шумеро-аккадского эпоса о Гильгамеше и поэм Гомера до русских «гисторий» о богатырях, зафиксированных письменно в XVII столетии и исполняющихся сказителями Севера до сих пор.

Согласно определению, данному во вступительной статье С.Ю. Неклюдовым и Н.В. Петровым, «книжным эпосом... в фольклористике и литературоведении обычно называют тексты древней и средневековой словесности, которые, как предполагается, непосредственно отражают устные эпические традиции, но затем получают окончательную обработку уже в ходе их литературной фиксации» [4, с. І2]. Понятие «книжный эпос» (приблизительными аналогами которого в мировой науке служат термины literary (или written) epic, transitive text, oral-derived text), обнимающее собой около двух десятков памятников, не является жанровым обозначением: как уточняет в другой своей статье С.Ю. Неклюдов, оно «обретает значимость только в той ситуации, когда появляется потребность отделить... эпические произведения, сохраненные лишь литературной традицией, от памятников “живого” эпоса, бытующих исключительно в устной словесности» [2, с. I6]. Отметим также, что границы этого - отчасти условного и «рабочего» - понятия очерчены достаточно строго: если монография 1978 г., посвященная данной теме, включала статью М.Л. Гаспарова и Е.Г. Рузиной о Вергилии, то 
в рецензируемой книге вергилиевский эпос отнесен к авторским произведениям (в статье И.В. Ершовой о романском эпосе), поскольку определяющей чертой книжного эпоса служит выраженная связь письменных памятников с фольклором, т. е. с принципами устного создания и исполнения произведений.

Связь эта может проявляться многими способами. Это и существенные различия в рукописях, обусловленные записью различных устных вариантов одного и того же сюжета, и особенности письменного текста, рассчитанного на устное исполнение (к примеру, группировка слов без пробелов в соответствии с метрическими характеристиками произведения; см.: [7]), и, наконец, главная черта эпической повествовательной техники, согласно знаменитой теории М. Пэрри и А. Лорда, - наличие в тексте значительного процента формул, т. е. соответствующих эпическому размеру фразеологических «блоков», каждый из которых используется в одних и тех же метрических позициях. При этом, как справедливо указывают составители монографии, речь идет о взаимосвязи письма и устного слова, далеко не всегда предполагающей генетическую зависимость первого от второго. «Главная проблема <...> заключается в том, какие сюжеты отбирают и устная и письменная традиции, каким образом устная традиция берет сюжеты из письменной, как письменная традиция работает с устными текстами, каждый раз добавляя и достраивая сюжет. В любой культуре, в которой существует относительно развитая грамотность, затрагивающая относительно демократические слои, эпос и фольклор всегда будут взаимодействовать с книжностью» [4, с. I3].

Действительно, проблема соотношения устного и письменного бытования эпических текстов, их связи с фольклором далеко не проста и остается дискуссионной. В ряде случаев у нас вообще отсутствуют сведения об устном распространении эпоса. Если, например, «Рамаяна» и «Махабхарата» складывались на протяжении веков (примерно с IV в. до н.э. до IIIIV вв. н.э.) в устной форме и факт устного исполнения отражен в самом их тексте, а записаны были «на поздней стадии бытования, когда обе поэмы достигли колоссального объема» [4, с. II9], то об устной ипостаси эпоса о Гильгамеше нам ничего не известно. Как пишет в своей статье Н.Г. Рудик, «мы знаем, что он использовался при обучении, что таблички с Эпосом держали во многих частных библиотеках <...>. Но что делали с этим 
текстом: читали, исполняли при дворе, использовали в культе или философских диспутах, - мы не знаем» [4, с. 77]. Эддическая поэзия, по словам И.Г. Матюшиной, «сочинялась в условиях, в которых создание, исполнение, сохранение и передача были не письменными, но устными», и ее архаизм «позволяет составить представление о древнейших стадиях развития словесности в Западной Европе» [4, с. 26I]. Напротив, в бесписьменной в целом древнеирландской культуре, где письменность использовалась для сугубо прагматических целей, сама оппозиция устного и письменного, по верному замечанию Т.А. Михайловой, оказывается лишена смысла: «...ексты, содержащие сведения космогонического и исторического характера, заучивались наизусть их носителями - друидами и передавались изустно (но в неизменной форме!) из поколения в поколение в особых школах» [4, c. I63]. «Похищение быка из Куальнге», образец ирландской героической саги - а точнее, «скела» (scél), как именовались в древней Ирландии подобные произведения, - скорее всего, на ранних стадиях своего существования также имело устную форму, но «его изначальная устность не была устностью фольклора» [4, с. г68], поскольку оно входило в целостную традицию псевдоисторического повествования, на которую оказывали воздействие как политические обстоятельства, так и книжные латинские образцы. О невозможности строгой дифференциации устного и письменного творчества в эпоху штауфенской классики начала XII в. пишет и А.Б. Рыкунова, анализируя «Песнь о Нибелунгах» и оговаривая при этом, что «Песнь...» предполагала устную рецитацию: речь может идти лишь «о нюансах и взаимопроникновении “устного” и “письменного” [4, с. 320]. Англосаксонский «Беовульф» предназначался не для устного исполнения, но для чтения, однако в нем, по словам И.Г. Матюшиной, сохранились «реликты жанров, восходящих к устной традиции и связанных в генезисе с магией и ритуалом (похоронные плачи, поминальные причитания, перебранки). Принадлежа к низовым жанрам англосаксонской поэзии, они наиболее близки к фольклору и, возможно, не предполагали письменной фиксации, но попали на страницы рукописи благодаря тому, что были включены в структуру книжного эпоса» [4, с. 2II]. Имеются и любопытные случаи прямого воздействия одной письменной традиции на другую. Описывая монгольские рукописные версии эпоса о Гесере, С.Ю. Неклюдов отмечает, что они отражают устные версии сказания, однако подражают тибетской книжной редакции и в 
своей композиции следуют тибетскому прототипу вплоть до нумерации его глав: отдельные рукописи изначально мыслятся и создаются как части целостного «виртуального» свода, материально зафиксированного в соседнем культурном ареале.

Наконец, изучение книжного эпоса и его бытования выявляет еще одну, не вполне обычную черту его связи с фольклором: в отдельных случаях устное исполнение текста выполняет магически-обрядовую функцию, которая переносится и на его письменную версию. Как пишет С.Ю. Неклюдов в той же статье о Гесериаде, рецитация тибетских сказаний «мыслилась как инспирированная героем, причем сказители впадали в транс»; при этом «не только устный, но и - прежде всего - книжный (рукописный, ксилографический) текст имел охранительное значение, его чтение использовалось в медицинских целях, для изгнания духов и пр.» [4, с. 4II]. Не менее интересна ситуация с русскими былинами, само название которых вошло в обиход (в том числе и у сказителей) в основном благодаря даже не рукописной традиции, но собирателям и исследователям фольклора, вытеснив эмический термин ста́рина, или стари́на: так обозначался жанр, включающий в себя, помимо самих былин, «исторические песни, баллады, скоморошины, некоторые духовные стихи - большинство из того, что можно пропеть былинным стихом» [4, с. 44I].

Таким образом, изучение книжного эпоса - как и само вычленение этой группы текстов из общего массива героических повествований - позволяет ставить и решать проблемы, далеко выходящие за рамки эпосоведения: речь идет не только о становлении и характеристиках одного из жанров или родов литературы, но и о зарождении литературы как таковой, о ее социально-культурной роли в различные эпохи, о соотношении коллективной традиции и индивидуального авторства, об эволюции поэтической техники и приемов ее фиксации. Изучение книжного эпоса требует, с одной стороны, строгого анализа сохранившихся рукописей (а иногда, как в случае с тибетско-монгольским эпосом о Гесере, и ксилографов) с точки зрения их содержательных и палеографических особенностей, а с другой реконструкции исторического бытования сказания и способов его отражения в манускриптах, возникавших на разных стадиях его существования.

Отдельный интерес представляет проблема, так сказать, «эпического авторства» - возведение в рамках традиции канонических эпических тек- 
стов к фигуре наиболее известного и уважаемого сказителя, будь то Гомер, Вьяса и Вальмики (легендарные создатели «Махабхараты» и «Рамаяны», соответственно) или ученый средневавилонского периода Син-леке-унинни, которому приписывается создание «Гильгамеша». Более того, проблема эта чаще всего напрямую связана именно с письменным бытованием эпоса. Так, возникновение в Греции алфавитного письма датируется приблизительно тем же временем, что и гомеровские поэмы (VIII в. до н.э.), что позволяет некоторым сторонникам «историчности» Гомера выводить заимствование алфавита из необходимости записать «Илиаду» и «Одиссею». Напротив, согласно «эволюционной теории» американского ученого Г. Надя, поэмы эти создавались in performance вплоть до эллинистического периода, а «гомеровская вульгата» была составлена на основе многочисленных вариантов филологами александрийской школы. Подтверждением этой теории служат так называемые «дикие», или «эксцентрические» папирусы - ранние фрагменты поэм, скорее всего, списки, использовавшиеся рапсодами и значительно отличающиеся от канонического текста. Просуществовав примерно до І50 г. до н.э., к началу первого века эти «дикие папирусы» практически исчезают. По точному замечанию Н.П. Гринцера, «историзация» фигуры Гомера в Античности «дает крайне интересный материал, в том числе и касательно самого имени легендарного поэта, которое древние понимали как “слепец” или “заложник”. Современные ученые чаще

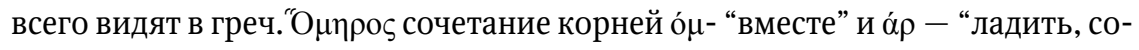
единять”. В результате Гомер предстает... “соединяющим вместе” отдельные фрагменты в единую песнь или отдельные слова в целостную ткань текста. Тем самым его имя оказывается своего рода идеальным эпонимом поэта, отражая самую суть поэтического искусства» [4, с. III].

Изучение книжного эпоса позволяет уточнить и центральное для эпического жанра понятие формуль. В статьях-главах монографии очерчивается широкий спектр вариаций, отличающих формульное повествование на протяжении многих столетий. По-видимому, наиболее полно отвечают классическому определению Пэрри-Лорда синонимические формулы «Рамаяны» и «Махабхараты», изначально приспособленные к эпическому размеру и встречающиеся в одних и тех же метрических условиях. Благодаря современным исследованиям «Илиады» и «Одиссеи» была выявлена основополагающая роль формул в генезисе древнегреческого эпического 
стиха, в возникновении гекзаметра: «...гекзаметр предстает результатом объединения более мелких метрических единиц, просодический рисунок которых близок структуре основных формул». Однако верно и обратное: «...гекзаметр, в свою очередь, порождает новые формулы и “приспосабливает” старые» [4, с. 94]. Между тем отнюдь не для всех произведений эта, одна из главных в эпосоведении, проблема в достаточной мере изучена: например, для «Старшей Эдды», как указывает И.Г. Матюшина, «темы» которые, согласно теории А. Лорда, образуют средний уровень эпического нарратива, промежуточный между формульным языком и песнью в целом, - до сих пор не становились объектом исследования.

Отдельный и чрезвычайно интересный вопрос связан с формульным характером прозаических эпических текстов, в которых формула по определению не может занимать «определенную метрическую позицию». В монографии на примере ирландской саги, огузского эпоса «Китаб-и дедем Коркут» («Книга моего деда Коркута») и монгольских редакций эпоса о Гесере (большинство тибетских версий имеет прозопоэтическую форму) показана специфика и роль формул в структуре повествованияг. Т.А. Аникеева, ссылаясь на определение американского исследователя И. Башгёза - формулы в прозаическом эпосе представляют собой устойчивые краткие словосочетания, виды которых обусловлены их местом в сюжете и композиции, - не только выделяет в «Книге Коркута» повторяющиеся ритмизованные фрагменты, прежде всего обращения героев к природе и «прорицания» заглавного героя, но и справедливо добавляет к их числу многочисленные пословицы и поговорки, присутствующие в эпосе. По мнению Т.А. Михайловой, стиль «Похищения быка из Куальнге», в котором практически полностью отсутствуют традиционные черты эпической поэтики, тем не менее включает формулы этикета и частые повторы, «которые выглядят как продуманные элементы поэтики текста» [4, с. І67].

Следует особо отметить, что рецензируемая книга представляет собой довольно редкий пример не просто сборника статей, объединенных общей темой, но настоящей коллективной монографии, все части которой, независимо от объема, строятся по единым принципам и подчинены единой структуре описания памятников. Это позволяет наглядно проследить неко-

I $\quad$ О формулах в прозаическом эпосе см.: [3]. 
торые их типологически сходные черты: как подчеркивают авторы вступительной статьи, эпос, в отличие от сказки, нечасто становится объектом прямого культурного заимствования. Среди них главное место занимают два важнейших для эпоса мотива, или темы, обусловленные его фольклорным происхождением, - оплакивание смерти героя и неразрывно связанное с ним понятие бессмертной славы, которое, как весьма уместно напоминает T.А. Михайлова, принадлежит к древнейшему слою индоевропейского языка. Герой обретает славу ценой своей смерти, придающей ему героический статус и выступающей материалом для создания эпической песни. «Именно в этом смысл выбора, совершаемого Ахиллом в “Илиаде” меж долгой, но безвестной жизнью и быстрой, но славной гибелью...», пишет Н.П. Гринцер [4, с. Iо2], а потому «плач по герою как отражение центральной организующей темы оказывается не только кульминацией действия поэмы, но и средоточием возможных корреляций между различными эпическими текстами» $[4$, с. I05].

Подобно «Илиаде» и «Одиссее», оплакиванием павших воинов завершаются оба индийских эпоса, «Махабхарата» и «Рамаяна», что позволяет говорить о плаче как о непременном атрибуте древнейшей эпики. Финалом первой части «Старшей Эдды» служат знаменитые строки о бессмертной славе умершего. В «Песни о Роланде» герой призывает соратников на битву, ссылаясь на «злые песни», которые сложат о них в случае, если они проявят недостаточную доблесть, и его отказ трубить в рог обусловлен той же заботой о посмертной славе. Зато в финале, по точному замечанию И.В. Ершовой, Роланд трубит в Олифант согласно той же логике эпического героя: он зовет короля не только отомстить за гибель своего войска, но и оплакать славную смерть погибших. Плач Карла Великого - центральная тема финальной части «Роланда» - свидетельствует о том, что оплакивание и панегирик герою выступают в эпосе одной из важнейших функций правителя. Из четырех основных «тем» старофранцузской песни - совет, плач, битва, смерть героя - две последние связаны с героем, а две первые с государем [4, с. 362-363].

В зависимости от времени возникновения эпоса и его записи плач о герое, оставаясь одним из определяющих жанровых атрибутов песни, принимает различные формы. Если на основе плачей гомеровского эпоса возможно реконструировать черты архаического погребального ритуала, 
то, например, два аналогичных фрагмента, входящие в «Беовульф», могут носить это имя с большой долей условности. «По своим жанровым признакам они более близки к элегиям, ибо сочиняются не в момент гибели тех, о ком скорбит герой, но тогда, когда память вынуждает вспомнить о них» [4, c. I89].

Конечно, эпоха и исторические обстоятельства накладывают отпечаток не только на формы плача, но и на поэтику эпоса в целом. Т.А. Михайлова в связи с сагами уладского цикла (повествования о воинах короля Конхобара), в который входит «Похищение быка из Куальнге», прослеживает эволюцию этих саг под влиянием политической и социальной ситуации в псевдоисторическое повествование, несущее в себе «агитационный» смысл. Повести о героическом прошлом, распространявшиеся в среде аристократии сказителями-филидами, отделились от рассказов, которые имели хождение «в народе», среди крестьян (о Финне и его воинах), и после многочисленных вариаций превратились в подобие волшебных сказок. Та же установка на историческую достоверность, отличающая эпос в целом, в «Песни о Роланде» подкрепляется ссылками на письменную хроникальную традицию - черта, которая по естественным причинам отсутствовала в эпосе архаическом. При этом если в тексте французской жесты прослеживается «последовательное сопротивление эпической основы» социокультурному контексту эпохи, в которую она была записана, то «Песнь о моем Сиде», повествующая о реальных и сравнительно недавних событиях, «являет собой... выразительный пример гибкой трансформации эпической модели под влиянием эпохи, и близость событий и памятника играет в этом немаловажную роль» [4, с. 378-379].

В рамках небольшой рецензии невозможно охватить все многообразие проблем, которые ставит перед исследователями книжный эпос и которые так или иначе нашли отражение в монографии. Это и вопрос о генезисе эпоса - главы книги в целом подтверждают теорию С. Боуры [г; 6] о происхождении героических сказаний из панегирика и плача, - и способы и обстоятельства его циклизации, и даже сама возможность выделения эпических циклов из совокупности тех или иных национальных сказаний, как в случае с ирландскими сагами. К слову, монография опровергает даже такой, казалось бы, очевидный тезис, что эпические сказания объединяются в циклы вокруг фигур героев-богатырей: центральной фигурой огузской 
«Книги моего деда Коркута» становится мудрый эпический певец, патриарх племени, чьи моральные наставления-«предсказания» завершают каждый рассказ, придавая тем самым тексту композиционную целостность.

Стоит упомянуть и еще об одном вопросе, который поднимается в статьях монографии, - дальнейшем бытовании эпоса в мировой и национальных культурах. Если, например, распространение эпоса о Гильгамеше, по-видимому, завершилось вместе с зафиксировавшей его клинописной традицией (однако сама его фигура сохранилась в памяти человечества в двух ипостасях - великий царь древности и воплощение злого, демонического начала), то «Рамаяна» и «Махабхарата» с их энциклопедизмом до сих пор сохраняют влияние на индийскую культуру, эстетику и мораль. «Сид» Корнеля, «Кольцо Нибелунгов» Вагнера, американский (I990) и итальянский (2010) кинофильмы «Золото Рейна» продолжают - разумеется, в трансформированном виде - жизнь старинных сказаний в иные эпохи и в иной культурной среде. В связи с этим чрезвычайно плодотворной представляется мысль, высказанная Н.В. Петровым применительно к русским былинам: «Дальнейшее формирование облика фольклорных персонажей и фольклора вообще в коллективной памяти связано... с массовостью образцов изобразительного искусства, школьного образования и кинематографа. Все это приводит к несколько другому пониманию читателем и зрителем в XXI в. (в отличие от понимания фольклористов) того, что такое эпос и шире - фольклор» [4, с. 466]. Влияние визуальных искусств на бытование эпоса, как и вообще словесных памятников прошлого, действительно огромно и могло бы послужить темой отдельного большого исследования. Одним из примеров, совмещающих в себе одновременно потребности образования, воспитание исторического взгляда на подобные памятники и возможности визуального ряда, может служить, скажем, вышедшая в 2004 г. во Франции детская адаптация знаменитого эпоса «Роланд в Ронсевальском ущелье» [8]. Воспроизведение сюжетной канвы «Песни о Роланде» сопровождается в ней высочайшего качества фотографиями предметов средневекового искусства, хранящихся в фондах Лувра.

Таким образом, монография «Памятники книжного эпоса Запада и Востока» представляет огромный интерес и ценность не только для эпосоведов и фольклористов, но и для самого широкого круга филологов и историков. Обстоятельные обзоры дошедших до нас рукописей, подробные 
аналитические сводки по истории вопроса и библиографические списки, содержащиеся в каждой главе, предметно-тематический указатель элементов эпического сюжета (составитель - С.С. Макаров), делают этот капитальный труд заметным событием в науке, и отнюдь не только в отечественной. Впечатление от него почти не портят отдельные опечатки и описки - иногда забавные, как, например, на с. 78, где говорится о «прямом влиянии Эроса (вместо Эпоса) о Гильгамеше», или на с. 37І, где «Сид восстанавливает честь и женит дочерей на инфантах Наварры и Арагона». Кроме того, как нам кажется, создаваемая в нем объемная картина мирового книжного эпоса была бы еще полнее, если бы в монографию вошла глава, например, об исландских сагах, однако масштаб и сложность поднятых в ней проблем позволяет рассчитывать на появление нового труда - и, возможно, раньше, чем еще через следующие сорок лет. 


\section{Список литературы}

\section{Исследования}

I Боура С.М. Героическая поэзия / пер. Н.П. Гринцера, И.В. Ершовой.

М.: Новое литературное обозрение, 2002. 792 с.

2 Неклюдов С.Ю. Эпос в мировой литературе // ШАГИ / STEPS. 2OI5. Т. І, № 2.

C. 7-22.

3 Неклюдов С.Ю. О стилистической организации монгольской «Гесериады» //

Памятники книжного эпоса. Стиль и типологические особенности.

М.: Наука, г978. С. 49-67.

4 Памятники книжного эпоса Запада и Востока: коллективная монография / сост. и ред. С.Ю. Неклюдов, Н.В. Петров. М.: ИНФРА-М, 2ог8. 482 с.

5 Памятники книжного эпоса. Стиль и типологические особенности / отв. ред.

E.M. Мелетинский. М.: Наука, І978. 272 с.

6 Bowra C.M. Heroic poetry. London: Macmillan, I952. IX, 590 p.

7 Busby K. Mise en texte as indicator of oral performance in Old French verse narrative //

Performing medieval narrative / ed. by E.B. Vitz, N.F. Regalado, M. Lawrence.

Cambridge; Rochester; NY, 2005. P. 6I-7I.

8 Censoir C., Heugel L. Roland à Roncevaux. Paris : Thierry Magnier / Louvre, 2004. 32 p. 


\section{References}

I Bowra, C.M. Geroicheskaia poeziia [Heroic Poetry]. Moscow, Novoe literaturnoe obozrenie Publ., 2002. 792 p. (In Russ.)

2 Nekliudov, S.Iu. "Epos v mirovoi literature" ["The Epic in World Literature"]. ShAGI / STEPS, vol. I, no. 2, 20I5, pp. 7-22. (In Russ.)

3 Nekliudov, S.Iu. "O stilisticheskoi organizatsii mongol'skoi 'Geseriady'." ["On the Stylistic Organization of the Mongolian 'Epic of King Gesar'.”] Pamiatniki knizhnogo eposa. Stil' i tipologicheskie osobennosti [Monuments of Book Epic. Style and Typology Features]. Moscow, Nauka Publ., I978, pp. 49-67. (In Russ.)

4 Neklyudov, S.Yu., and N.V. Petrov, editors. Pamiatniki knizhnogo eposa Zapada $i$ Vostoka [Monuments of Book Epic of West and East]. Moscow, INFRA-M Publ., 2018. 482 p. (In Russ.)

5 Meletinski E.M., editor. Pamiatniki knizhnogo eposa. Stil' i tipologicheskie osobennosti [Monuments of Book Epic. Style and Typology Features]. Moscow, Nauka Publ., I978. 272 p. (In Russ.)

6 Bowra, Cecil Maurice. Heroic poetry. London, Macmillan, I952. IX, 590 p. (In English)

7 Busby, Keith. "Mise en texte as Indicator of Oral Performance in Old French Verse Narrative.” Vitz E.B., and N.F. Regalado, and M. Lawr, editors. Performing medieval narrative. Cambridge, Rochester, NY, 2005, pp. 6I-7I. (In English)

8 Censoir, Charlotte, Heugel, Louise. Roland à Roncevaux. Paris, Thierry Magnier / Louvre, 2004. 32 p. (In French) 